\title{
Changes in metal availability, desorption kinetics and speciation in contaminated soils during repeated phytoextraction with the $\mathrm{Zn} / \mathrm{Cd}$ hyperaccumulator Sedum plumbizincicola
}

\author{
Zhu Li ${ }^{\text {a }}$, Mingyun Jia ${ }^{\text {b }}$, Longhua $\mathrm{Wu}^{\text {a, * }}$, Peter Christie ${ }^{\text {a }}$, Yongming Luo ${ }^{\text {a, }}$ \\ ${ }^{a}$ Key Laboratory of Soil Environment and Pollution Remediation, Institute of Soil Science, Chinese Academy of Sciences, Nanjing 210008, China \\ b State Key Laboratory of Soil and Sustainable Agriculture, Institute of Soil Science, Chinese Academy of Sciences, Nanjing 210008, China \\ ${ }^{\mathrm{c}}$ Key Laboratory of Coastal Zone Environmental Processes, Yantai Institute of Coastal Zone Research, Chinese Academy of Sciences, Yantai 264003, China
}

\section{A R T I C L E I N F O}

\section{Article history:}

Received 29 August 2015

Received in revised form

11 November 2015

Accepted 12 November 2015

Available online 7 December 2015

\section{Keywords:}

Agricultural soils

Metal pollution

Phytoremediation

Availability

Metal desorption

\begin{abstract}
A B S T R A C T
Phytoextraction is one of the most promising technologies for the remediation of metal contaminated soils. Changes in soil metal availability during phytoremediation have direct effects on removal efficiency and can also illustrate the interactive mechanisms between hyperaccumulators and metal contaminated soils. In the present study the changes in metal availability, desorption kinetics and speciation in four metal-contaminated soils during repeated phytoextraction by the zinc/cadmium hyperaccumulator Sedum plumbizincicola (S. plumbizincicola) over three years were investigated by chemical extraction and the DGT-induced fluxes in soils (DIFS) model. The available metal fractions (i.e. metal in the soil solution extracted by $\mathrm{CaCl}_{2}$ and by EDTA) decreased greatly by $>84 \%$ after phytoextraction in acid soils and the deceases were dramatic at the initial stages of phytoextraction. However, the decreases in metal extractable by $\mathrm{CaCl}_{2}$ and EDTA in calcareous soils were not significant or quite low. Large decreases in metal desorption rate constants evaluated by DIFS were found in calcareous soils. Sequential extraction indicated that the acid-soluble metal fraction was easily removed by S. plumbizincicola from acid soils but not from calcareous soils. Reducible and oxidisable metal fractions showed discernible decreases in acid and calcareous soils, indicating that S. plumbizincicola can mobilize non-labile metal for uptake but the residual metal cannot be removed. The results indicate that phytoextraction significantly decreases metal availability by reducing metal pool sizes and/or desorption rates and that S. plumbizincicola plays an important role in the mobilization of less active metal fractions during repeated phytoextraction.
\end{abstract}

(c) 2015 Elsevier Ltd. All rights reserved.

\section{Introduction}

Metal pollution of some soils has become a serious environmental concern and a potential threat to human health. The technique of phytoextraction using hyperaccumulators has been shown to be successful in remediating soils polluted with metals (McGrath et al., 2006; Japenga et al., 2007; Li et al., 2012). However, the technique requires long periods of remediation effort and successive or numerous crops are needed to remove adequate metal from contaminated soils to achieve safe levels (Koopmans et al., 2008; Li et al., 2014). During the process of phytoextraction soil metal availability will change as prolonging the remediation time increases interactions between soil and plant. Both short-term

\footnotetext{
* Corresponding author.

E-mail address: lhwu@issas.ac.cn (L. Wu).
}

phytoextraction and rhizosphere experiments on hyperaccumulators show clear decreases in soil metal availability in contaminated soils after phytoextraction and in rhizosphere soils as compared to bulk soils (Keller and Hammer, 2004; Liu et al., 2011). However, after short-term phytoextraction the decreased available metal may be replenished through soil metal re-equilibration (Keller and Hammer, 2004). Investigation of metal availability changes over relatively long time periods may help to elucidate metal changes and to alleviate the environmental risk of metals due to phytoextraction. In addition, compared to short-term phytoextraction, the enhanced plant-soil interactions and more marked decrease in soil metals during long periods of phytoextraction can give more information on the mechanisms of phytoextraction. Moreover, the efficiency of remediation can decrease during repeated phytoextraction as shown by Li et al. (2014), and the further discrimination of changes in soil metals during phytoextraction might help to elucidate the factors involved. 
Numerous methods have been used to investigate the behavior of metals in soils. Chemical extraction tests are among the most commonly and widely used methods for predicating or estimating the bioavailability of various forms of metals (D'Amore et al., 2005). Choice of chemical agent depends on the specific points of interest of the study. Concentrated acids are usually used as to determine total amounts of metals present and estimate the total potentially harmful metals. Soil solution metal or weaker agents extractable metal fractions are relatively soluble and bioavailable. The waterextractable or soil solution metals are commonly considered to be the most readily available fraction to biota (Seguin et al., 2004). Weak chemical agents, e.g. $\mathrm{CaCl}_{2}, \mathrm{Ca}\left(\mathrm{NO}_{3}\right)_{2}$ and $\mathrm{BaCl}_{2}$, extract fractions that have been used to denote metal availability to plants as shown in some studies (Peijnenburg et al., 2007; Meers et al., 2007a). Extraction with $0.01 \mathrm{M} \mathrm{CaCl}_{2}$ has been suggested for estimating metal availability (Novozamsky et al., 1993; Houba et al., 2000) and gives a good indication of metal availability to plants (Meers et al., 2007b). The metal fraction extracted by EDTA is used to denote potentially available and mobile metal due to the strong metal complexing ability of EDTA (Anju and Banerjee, 2011). Sequential extraction tests have been used widely to investigate metal physico-chemical forms and to study the effects of soil processes and changes in environmental conditions on soil metal availability and mobility. The three-step procedure proposed and modified by the Community Bureau of Reference (BCR) (Ure et al., 1993; Sahuquillo et al., 1999) has been widely accepted as the 'standard method' and its application has increased recently (Pueyo et al., 2008; Anju and Banerjee, 2011). In the present study, single extracts with different extraction abilities (i.e. soil solution, $\mathrm{CaCl}_{2}$ and EDTA) and the BCR test were used to investigate changes in metal availability and combined forms during long-term phytoextraction.

Soil metal mobility and availability depend largely on metal desorption from the soil solid phase and on metal concentration in the soil solution. If metal desorption from the solid phase is kinetically limited then this may be a factor limiting plant metal uptake (Zhang et al., 2006). The technique of diffusive gradients in thin films (DGT) is based on kinetic principles and can reflect the soil metal desorption process when metals in the soil solution are depleted at the interface between the roots and the soil (Davison et al., 2000). The kinetic information can be obtained by the model of DGT induced fluxes in soils (DIFS). The DIFS model has been used to study the metal desorption kinetics of contaminated soils (Ernstberger et al., 2005; Zhang et al., 2006) and changes in metal desorption kinetics induced by hyperaccumulators (Fitz et al., 2003). In the present study the changes in soil metal desorption kinetics during the repeated phytoextraction of four metal-contaminated soils with contrasting soil properties were investigated using the DIFS model.

The plant metal uptake and remediation efficiency of four metal-contaminated soils in long-term phytoextraction has been investigated in a previous study (Li et al., 2014). In the present study soil metal changes during the long-term phytoextraction were further investigated by single and sequential extractions and using the DIFS model. The aim was to elucidate changes in metal availability, associated forms and desorption kinetics in the different soils and to understand the possible soil metal processes induced by interactions between soil and plant during long-term phytoextraction.

\section{Methods and materials}

\subsection{Soil characterization}

Four types of metal contaminated soil were collected from the arable layer (top $15 \mathrm{~cm}$ ) of agricultural fields in different parts of China. Two acid soils were collected from Dabaoshan in Guangdong Province, south China, and Huludao in Liaoning Province, north China, and are referred to as DBS and HLD, respectively. The soil from DBS is a Ferralic Anthrosols that has been polluted by metal mining activities and the soil from HLD is a Haplic Lixixols whose main pollution source is a zinc factory that has operated for several decades. The other two soils are calcareous soils which were collected from Zhujiawu and Shuanglingdong in Zhejiang Province, east China, and are labeled ZJW and SLD, respectively. They are from an area polluted by a copper smelter and the soil type is Hydragric Anthrosols. Each of the four contaminated soils was first air-dried and then passed through a 2-mm nylon sieve and mixed thoroughly. The metal contaminated soils were continuously phytoextracted using Sedum plumbizincicola for three years over seven successive crops in a glasshouse located in Nanjing. Soil samples were collected after the third harvest (P3) and the seventh harvest (P7) during long-term phytoextraction. Together with the soils without remediation (NP) there were a total of three types of soil samples with different cropping phytoextraction collected from the pot experiment during the experiment. After phytoextraction by seven crops the total $\mathrm{Zn}$ concentrations in the DBS, HLD, SLD and ZJW soils (P7) decreased by $37,52,12$, and $19 \%$, respectively, and Cd concentrations decreased by $64,89,37$, and $38 \%$ compared to the NP soil (Table 1). All these soil samples were firstly air-dried, then passed through a 2-mm nylon sieve and were used to evaluate the soil metal changes induced by phytoextraction.

Portions of the sieved soils were used for determination of selected soil chemical properties. Soil $\mathrm{pH}$, soil total organic carbon (TOC), soil cation exchange capacity (CEC), and soil total metal were analyzed by previously published methods (Li et al., 2014). Free iron/aluminum oxides $\left(\mathrm{Fe}_{\mathrm{d}} / \mathrm{Al}_{\mathrm{d}}\right)$ were extracted with $\mathrm{Na}_{2} \mathrm{~S}_{2} \mathrm{O}_{4}-\mathrm{Na}_{3} \mathrm{C}_{6} \mathrm{H}_{5} \mathrm{O}_{7}-\mathrm{NaHCO}_{3}$ and determined by atomic absorption spectrophotometry (Varian SpectrAA 220FS, Varian, Palo Alto, CA). The particle size distribution was determined with a Beckman LS230 laser diffraction apparatus. Selected chemical properties of the contaminated soils with or without phytoextraction are shown in Table 1.

\subsection{Calculation of DGT concentration and DIFS}

Information on the standard piston DGT devices and the method of calculation of DGT concentration were described in a previous study (Li et al., 2014). In brief, the concentration of metal at the interface of the DGT device and the soil $\left(C_{\mathrm{DGT}}\right)$ was calculated as follows,

$C_{\mathrm{DGT}}=C_{\mathrm{E}}\left(V_{\mathrm{HNO}_{3}}+V_{\mathrm{gel}}\right) \Delta g / t A D f_{\mathrm{e}}$

Where $C_{\mathrm{E}}$ is the concentration of metal in the $1 \mathrm{M} \mathrm{HNO}_{3}$ elution solution $\left(\mu \mathrm{g} \mathrm{l}^{-1}\right), V_{\mathrm{HNO}}$ is the volume of $\mathrm{HNO}_{3}$ added to the resin gel $(1 \mathrm{ml}), V_{\text {gel }}$ is the volume of the resin gel, typically $0.15 \mathrm{ml} f_{e}$ is the elution factor for each metal, typically $0.8, \mathrm{t}$ is the deployment time (in sec), $A$ is the exposure area, typically $2.54 \mathrm{~cm}^{2}, \Delta g$ is the thickness of the diffusive gel $(0.08 \mathrm{~cm})$ plus the thickness of the filter membrane $(0.014 \mathrm{~cm})$, and $D$ is the diffusion coefficient of the metal in the gel.

Comparing the concentration of $C_{\mathrm{DGT}}$ to the measured soil solution (gained by centrifugation as described in Li et al. (2014) concentration $\left(C_{\text {soln }}\right)$ provides a ratio, $R$, which is dimensionless and gives an indication of the extent of the depletion of the soil solution concentration at the interface with the DGT:

$R=C_{\mathrm{DGT}} / C_{\mathrm{soln}}$ 
Table 1

Chemical properties of four contaminated soils with or without repeated phytoextraction.

\begin{tabular}{|c|c|c|c|c|c|}
\hline Soil property & With or without phytoextraction & DBS & HLD & SLD & ZJW \\
\hline Sand (\%) & NP & 22.6 & 32.0 & 31.4 & 35.6 \\
\hline Silt $(\%)$ & NP & 49.8 & 57.8 & 56.0 & 50.8 \\
\hline Clay (\%) & NP & 25.6 & 10.2 & 12.6 & 13.6 \\
\hline WHC (\%) & NP & 35.4 & 25.7 & 31.6 & 30.2 \\
\hline $\mathrm{CEC}\left(\mathrm{cmol} \mathrm{kg}^{-1}\right)$ & NP & 8.31 & 15.4 & 18.9 & 11.2 \\
\hline \multirow[t]{2}{*}{ TOC $\left(\mathrm{g} \mathrm{kg}^{-1}\right)$} & NP & 24.3 & $15.1^{*}$ & $28.4^{*}$ & $19.5^{*}$ \\
\hline & P7 & 23.7 & 13.2 & 25.7 & 11.2 \\
\hline \multirow[t]{2}{*}{$\mathrm{CaCO}_{3}(\%)$} & NP & - & - & $8.78^{*}$ & $2.22^{*}$ \\
\hline & P7 & - & - & 7.93 & 1.62 \\
\hline \multirow[t]{2}{*}{$\mathrm{Fe}_{\mathrm{d}} / \mathrm{Al}_{\mathrm{d}}(\%)$} & NP & $7.76^{*} / 0.17$ & $2.74 / 0.13$ & $3.82^{*} / 0.79$ & $1.61^{*} / 0.64$ \\
\hline & P7 & $8.19 / 0.18$ & $2.61 / 0.13$ & $5.41 / 0.80$ & $2.47 / 0.65$ \\
\hline \multirow[t]{2}{*}{$\mathrm{pH}\left(\right.$ in $\left.\mathrm{H}_{2} \mathrm{O}\right)$} & NP & 3.71 & 4.77 & 7.74 & $7.14^{*}$ \\
\hline & P7 & 3.87 & 4.71 & 7.71 & 7.72 \\
\hline \multirow[t]{2}{*}{ Total $\mathrm{Zn}\left(\mathrm{mg} \mathrm{kg}^{-1}\right)$} & NP & $291^{*}$ & $476^{*}$ & $1308^{*}$ & $1201^{*}$ \\
\hline & P7 & 183 & 229 & 1146 & 978 \\
\hline \multirow[t]{2}{*}{ Total Cd ( $\left.\mathrm{mg} \mathrm{kg}^{-1}\right)$} & NP & $0.42^{*}$ & $8.68^{*}$ & $16.9^{*}$ & $2.28^{*}$ \\
\hline & P7 & 0.15 & 0.93 & 10.5 & 1.43 \\
\hline
\end{tabular}

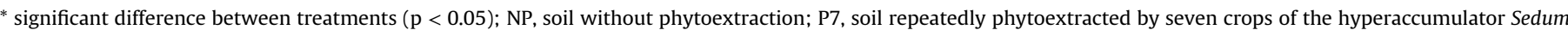

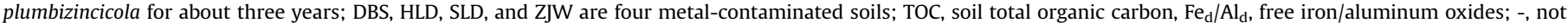
determined.

The DIFS model can quantify the dependence of $R$ on the resupply of the metals from soil solid phase to solution coupled to diffusional supply to the interface and across the diffusion layer to the resin gel. $R$ is mainly dependent on two key parameters, $K_{\mathrm{d}}$ and $T_{\mathrm{c}} . K_{\mathrm{d}}$ is the distribution coefficient defined by all species adsorbed to the solid phase that can exchange with the solution phase and can be measured by DGT. $T_{\mathrm{c}}$ is the response time of the metal adsorption-desorption process (Degryse et al., 2009). The DIFS model uses $K_{\mathrm{d}}$ and $T_{\mathrm{c}}$ to describe the kinetics of adsorption (rate constant, $k_{1}$ ) and desorption (rate constant, $k_{-1}$ ) (Equations (3) and (4)).

$K_{\mathrm{d}}=\frac{C_{\text {solid }}}{C_{\text {solution }}}=\frac{k_{1}}{P_{\mathrm{c}} k_{-1}}$

$T_{\mathrm{c}}=\frac{1}{k_{1}+k_{-1}}=\frac{1}{k_{-1}\left(1+K_{\mathrm{d}} P_{\mathrm{c}}\right)} \approx \frac{1}{k_{-1} K_{\mathrm{d}} P_{\mathrm{c}}}$

$P_{\mathrm{C}}$ is the soil particle concentration. $K_{\mathrm{d}}$ and $R$ are input parameters, and the DIFS model can calculate the response time $\left(T_{\mathrm{c}}\right)$ of soil solid phase metal to the depletion in soil solution induced by DGT. The metal kinetic desorption $\left(k_{-1}\right)$ rate constant can be obtained based on Equation (4). In this study the difference between soil total metal and residual metal based on the BCR test is regarded as $C_{\text {solid }}$ for $K_{\mathrm{d}}$ estimation.

\subsection{Soil metal analysis}

\subsubsection{Metal concentrated by DGT}

NP soil samples (without phytoextraction), P3 (with three croppings of phytoextraction) and P7 (with seven croppings of phytoextraction) were used for DGT deployment. The deployment of DGT and the metal determination have been described previously by Li et al. (2014).

\subsubsection{Soil metal extraction}

Soil samples NP, P3 and P7 were used for metal extraction with $\mathrm{CaCl}_{2}$ and EDTA. (1) Air-dried soil (2 g) was extracted with $0.01 \mathrm{M}$ $\mathrm{CaCl}_{2}$ (soil: extractant ratio $1: 10$ ) by shaking at $19{ }^{\circ} \mathrm{C}$ for $2 \mathrm{~h}$, then centrifuging (10 min at $3000 \mathrm{rpm}$ ) and filtering. Cadmium and $\mathrm{Zn}$ concentrations in the supernatant were measured by ICP-MS (Varian Ultramass) within various calibration ranges using $\mathrm{Rh}$ as internal standard. Air-dried soil ( $2 \mathrm{~g}$ ) was extracted with 0.05 EDTA (soil: extractant ratio $1: 10$ ) by shaking at $25{ }^{\circ} \mathrm{C}$ for $1 \mathrm{~h}$, then centrifuging ( $3 \mathrm{~min}$ at $3000 \mathrm{rpm}$ ) and filtering. Extractable $\mathrm{Cd}$ and $\mathrm{Zn}$ in the filtrate were then determined by atomic absorption spectrophotometry (Varian SpectrAA 220FS; Varian, Palo Alto, CA).

Air-dried samples of soils NP, P3 and P7 (2.00 g) were used for extraction using the modified BCR (Community Bureau of Reference) sequential extraction procedure following Luo and Christie (1998). The certified reference material BCR701 was also extracted along with the soil samples for quality control. All sample recoveries (sum of four fractions/total in soil $\times 100$ ) were between 85 and $115 \%$.

\subsection{Statistical analysis}

Statistical analysis was performed by one-way analysis of variance (ANOVA) with Duncan's multiple range test at the 5\% level to compare the mean values using the SPSS version 16.0 for Windows software package. Data are presented as mean \pm standard error of the mean (SEM, $\mathrm{n}=3$ ).

\section{Results and discussion}

\subsection{Changes in soil parameters after repeated phytoextraction}

The changes in selected parameters during repeated phytoextraction were determined (Table 1). Compared to the soils without phytoextraction (NP), in the soils with seven croppings of $S$. plumbizincicola there was an apparent decrease in soil organic carbon. This may result from activities during the repeated phytoextraction, e.g. continuous cultivation combined with plant shoot removal and chemical fertilizer application causing the rapid mineralization of soil organic carbon. Soil $\mathrm{pH}$ changes were different for soils after phytoextraction. Increases in soil $\mathrm{pH}$ were observed in soil ZJW but no significant changes were found in DBS, HLD or SLD after repeated phytoextraction. This suggests that there was no unambiguous trend of changing soil $\mathrm{pH}$ induced by the process of repeated phytoextraction in this study. The content of calcium carbonate in calcareous soils SLD and ZJW showed an apparent decline (by 9.68 and $27.0 \%$, respectively) after phytoextraction. This might result from plant root and soil microbial activities involving the release of $\mathrm{H}^{+}$. In addition, the amounts of free iron oxides $\left(\mathrm{Fe}_{\mathrm{d}}\right)$ in all soils increased with the sole exception of 
Table 2

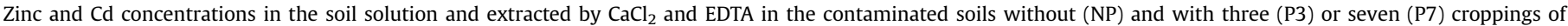

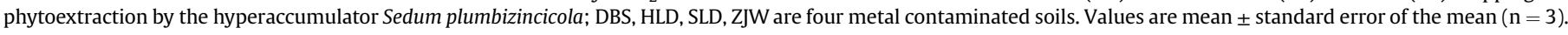

\begin{tabular}{|c|c|c|c|c|c|c|c|}
\hline \multirow[t]{2}{*}{ Fraction } & \multirow[t]{2}{*}{ Soil } & \multicolumn{3}{|c|}{$\mathrm{Zn}\left(\mathrm{mg} \mathrm{L}^{-1} / \mathrm{mg} \mathrm{kg}^{-1}\right)$} & \multicolumn{3}{|c|}{$\mathrm{Cd}\left(\mu \mathrm{g} \mathrm{L}^{-1} / \mu \mathrm{g} \mathrm{kg}^{-1}\right)$} \\
\hline & & NP & P3 & P7 & NP & P3 & P7 \\
\hline \multirow[t]{4}{*}{ Soil solution } & DBS & $21.4 \pm 0.3$ & $3.33 \pm 0.4$ & $1.05 \pm 0.10$ & $112 \pm 4$ & $19.1 \pm 3.2$ & $12.0 \pm 1.7$ \\
\hline & HLD & $15.9 \pm 0.5$ & $0.45 \pm 0.02$ & $0.16 \pm 0.01$ & $373 \pm 7$ & $8.30 \pm 0.72$ & $2.01 \pm 0.05$ \\
\hline & SLD & $0.09 \pm 0.01$ & $0.03 \pm 0.01$ & $0.02 \pm 0.00$ & $20.9 \pm 1.9$ & $4.73 \pm 0.06$ & $2.31 \pm 0.12$ \\
\hline & ZJW & $0.13 \pm 0.01$ & $0.03 \pm 0.00$ & $0.02 \pm 0.00$ & $4.93 \pm 0.41$ & $1.44 \pm 0.10$ & $0.90 \pm 0.07$ \\
\hline \multirow[t]{4}{*}{$\mathrm{CaCl}_{2}^{\mathrm{a}}$} & DBS & $29.8 \pm 0.5$ & $7.63 \pm 0.43$ & $2.37 \pm 0.15$ & $226 \pm 3$ & $51.0 \pm 6.8$ & $30.3 \pm 3.3$ \\
\hline & HLD & $62.7 \pm 0.4$ & $12.6 \pm 0.8$ & $3.99 \pm 0.22$ & $2230 \pm 92$ & $338 \pm 29$ & $88.4 \pm 2.8$ \\
\hline & SLD & $0.12 \pm 0.01$ & $0.14 \pm 0.01$ & $0.09 \pm 0.01$ & $77.5 \pm 11.8$ & $71.5 \pm 3.1$ & $30.9 \pm 1.4$ \\
\hline & ZJW & $0.28 \pm 0.00$ & $0.20 \pm 0.07$ & $0.21 \pm 0.02$ & $22.7 \pm 0.3$ & $20.0 \pm 1.3$ & $7.20 \pm 0.10$ \\
\hline \multirow[t]{4}{*}{ EDTA } & DBS & $20.8 \pm 0.2$ & $5.06 \pm 0.62$ & $3.39 \pm 0.89$ & $205 \pm 89$ & $22.6 \pm 2.6$ & $10.8 \pm 1.7$ \\
\hline & HLD & $60.4 \pm 0.8$ & $15.6 \pm 0.52$ & $6.59 \pm 0.61$ & $2300 \pm 42$ & $258 \pm 17$ & $85.8 \pm 2.9$ \\
\hline & SLD & $40.8 \pm 0.52$ & $40.2 \pm 0.8$ & $39.9 \pm 0.6$ & $3310 \pm 56$ & $2670 \pm 22$ & $1880 \pm 68$ \\
\hline & ZJW & $44.6 \pm 7.9$ & $32.0 \pm 1.6$ & $30.4 \pm 0.6$ & $499 \pm 22$ & $352 \pm 8$ & $271 \pm 6$ \\
\hline
\end{tabular}

a The $\mathrm{CaCl}_{2}$-extracted metal data are cited from Li et al. (2014).

DBS, and this was more pronounced in the calcareous soils. For example, after phytoextraction the increases in $\mathrm{Fe}_{\mathrm{d}}$ in SLD and ZJW were 41.6 and $53.4 \%$, respectively, compared to the soils without phytoextraction. Plant rhizosphere activities might be responsible for the changes. The release of $\mathrm{H}^{+}$and organic materials by roots may dissolve and complex iron and aluminum (Fujii, 2014), and in the partially anaerobic conditions of the rhizosphere some microbial activities might release iron or manganese by using them as terminal electron acceptors (Hoefer et al., 2015). The above chemical or biochemical activities might be beneficial to the transformation of other iron forms to $\mathrm{Fe}_{\mathrm{d}}$.

\subsection{Changes in metal availability during repeated phytoextraction}

Metals in the soil solution and extracted by $\mathrm{CaCl}_{2}$ and EDTA can be used as an indicator of the directly available fractions, more readily bioavailability, and potential availability for biota, respectively (Novozamsky et al., 1993; Houba et al., 2000; Seguin et al., 2004; Meers et al., 2007b; Anju and Banerjee, 2011). These three metal fractions were used here to discriminate changes in metal availability during repeated phytoextraction and the data are shown in Table 2. After phytoextraction with seven crops, soil solution $\mathrm{Zn}$ and $\mathrm{Cd}$ decreased markedly (by $>74 \%$ ) and the highest decrease $(>99 \%)$ was found in the acid soil HLD. Although soil solution metal concentrations decreased with increasing remediation cropping, sharp decreases were found at the first three croppings and the differences between soils with 3 and 7 phytoextraction croppings were small (Table 2). This indicates the slow release of the remaining soil metal at the later stages of repeated phytoextraction which might be related to the decrease in available metal pool sizes and increases in binding forces to the soil solid phase. Compared to DBS soil with lower total Cd and Zn, the severely Cdcontaminated soil HLD had lower soil solution $\mathrm{Cd}$ and $\mathrm{Zn}$ with repeated phytoextraction (Table 2 ). This may result from the low soil $\mathrm{pH}$ of DBS (3.71 for NP, and 3.87 for P, Table 1) which facilitates the distribution of metals into the soil solution. Similarly, because of high soil $\mathrm{pH}$ (over 7, Table 1), soil metals might precipitate as hydroxides or combined with carbonates (Du Laing et al., 2009), which might be responsible for the several magnitudes lower soil solution metal found in the calcareous soils than in the acid soils (Table 2).

When soil solution metal is considered as the fraction directly available to the plant, the amount of metal extracted by $\mathrm{CaCl}_{2}$ and EDTA reflects the size of two pools with different bioavailability. The acid soils without phytoextraction had higher available metal pool sizes (extracted by $\mathrm{CaCl}_{2}$ ) than the calcareous soils but the metal concentrations in potentially available pools (determined by extraction with EDTA) were of the same magnitude (Table 2). During repeated phytoextraction the changes in extractable metals by $\mathrm{CaCl}_{2}$ and EDTA depended on the soils. The extractable $\mathrm{Zn}$ and $\mathrm{Cd}$ by $\mathrm{CaCl}_{2}$ and EDTA decreased greatly (by 84-96\%) after seven croppings of phytoextraction in the acid soils and the trends of decline were similar to metals in the soil solution, showing dramatic changes at the initial stages of phytoextraction. This indicates that the metal declines in the soil solution are controlled mainly by the decreases in the available metal pool sizes in acid soils during phytoextraction. Previous studies show that hyperaccumulators can significantly decrease soil metal availability (Keller and Hammer, 2004; Dessureault-Rompre et al., 2010; Liu et al., 2011), but if just short-term phytoextraction is conducted the decreased available metal can be offset as the soil metals rebalance when phytoextraction ceases (Keller and Hammer, 2004). In the longterm repeated phytoextraction of the present study, metal extracted by $\mathrm{CaCl}_{2}$ and EDTA showed clear decreasing trends during phytoextraction of the acid soils. These results indicate that phytoextraction shows outstanding effects in reducing metal environmental risk. However, in the calcareous soils there was no significant change in either $\mathrm{CaCl}_{2}$-or EDTA-extractable $\mathrm{Zn}$ during phytoextraction. This could be related to the supplementation of $\mathrm{Zn}$ from less available pools because of the large buffering capacity for $\mathrm{Zn}$ in the calcareous soils. Although the available metal pool sizes did not decline the soil $\mathrm{Zn}$ environmental risk was to some extent also alleviated. This is due to the soil $\mathrm{Zn}$ desorption rates showing large decreases after phytoextraction as discussed below in the next section. Moreover, in long-term phytoextraction the available metal pool size must be decreased with further increase in phytoextraction time and this is confirmed by the absence of significant changes in $\mathrm{CaCl}_{2}$-extractable $\mathrm{Cd}$ after three croppings of S. plumbizincicola but a clear decrease after seven croppings (Table 2). The above results indicate that the target of phytoextraction in acid soils can be decreases in soil metal availability, but in calcareous soils should be based on the decline in the total metal concentration when there are no clear decreases in available fractions because of their high metal replenishment capacity.

\subsection{Metal desorption kinetics based on the DIFS model}

Knowledge of metal mobility and availability in soils depends on soil solution metals and available metal pool sizes in the solid phase, and metal desorption connects these two aspects. The dynamic DIFS model of the soil-DGT system is used here to obtain information on the changes in metal desorption kinetics during 
Table 3

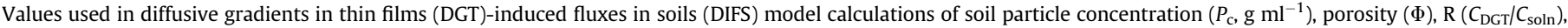
metal distribution coefficient between soil solid and solution $K_{\mathrm{d}}$ for the contaminated soils without and with different numbers of phytoextraction croppings.

\begin{tabular}{|c|c|c|c|c|c|c|c|c|c|c|c|c|c|c|}
\hline \multirow[t]{3}{*}{ Soil } & \multirow[t]{3}{*}{$P_{\mathrm{c}}$} & \multirow[t]{3}{*}{$\Phi$} & \multicolumn{6}{|l|}{$\mathrm{R}^{\mathrm{a}}$} & \multicolumn{6}{|l|}{$K_{\mathrm{d}}$} \\
\hline & & & \multicolumn{3}{|l|}{$\mathrm{Zn}$} & \multicolumn{3}{|l|}{$\mathrm{Cd}$} & \multicolumn{3}{|l|}{$\mathrm{Zn}$} & \multicolumn{3}{|l|}{$\mathrm{Cd}$} \\
\hline & & & NP & P3 & P7 & $\mathrm{NP}$ & P3 & P7 & $\mathrm{NP}$ & P3 & P7 & $\mathrm{NP}$ & P3 & P7 \\
\hline DBS & 2.0 & 0.57 & 0.13 & 0.17 & 0.16 & 0.13 & 0.15 & 0.14 & 13.6 & 58.5 & 174 & 3.75 & 8.37 & 12.5 \\
\hline HLD & 2.9 & 0.48 & 0.31 & 0.77 & 0.83 & 0.29 & 0.66 & 0.64 & 30.0 & 655 & 1970 & 23.3 & 228 & 462 \\
\hline SLD & 2.1 & 0.56 & 0.95 & 0.89 & 0.66 & 0.80 & 0.70 & 0.56 & 14100 & 38200 & 47400 & 807 & 2770 & 4540 \\
\hline ZJW & 2.1 & 0.56 & 0.90 & 0.69 & 0.62 & 0.60 & 0.48 & 0.38 & 8980 & 39800 & 39000 & 462 & 1200 & 1590 \\
\hline
\end{tabular}

a Denotes that R value data are cited from Li et al. (2014); $C_{\mathrm{DGT}}$ is the concentration of metal measured by DGT; $C_{\text {soln }}$ is the concentration of metal measured in the soil

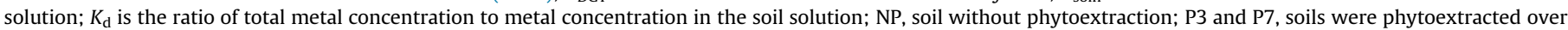
three and seven crops of the hyperaccumulator Sedum plumbizincicola, respectively; DBS, HLD, SLD, ZJW are four metal-contaminated soils.
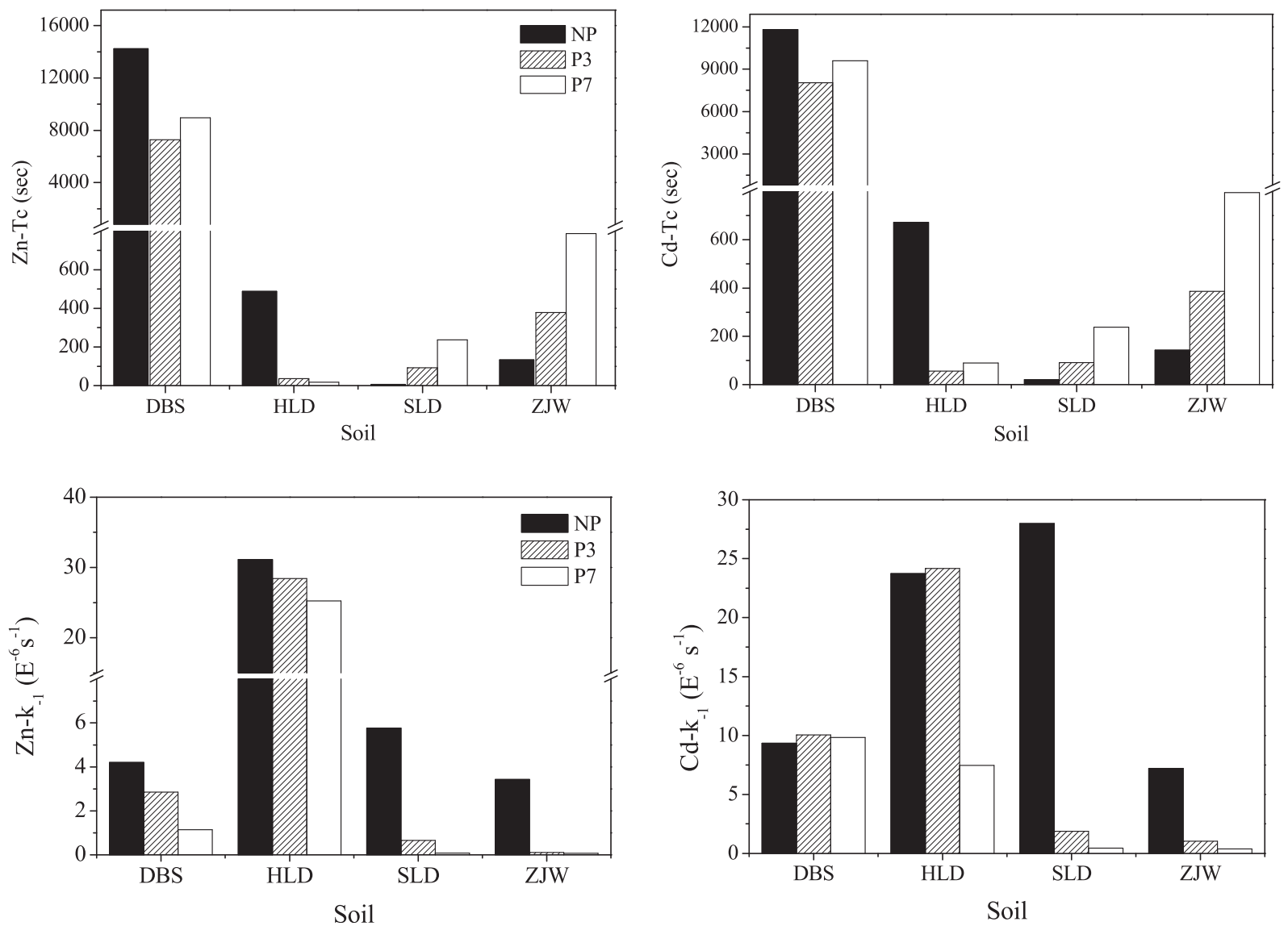

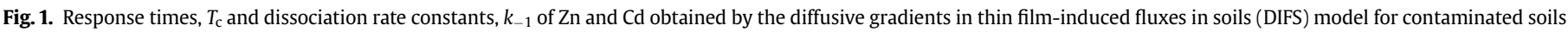

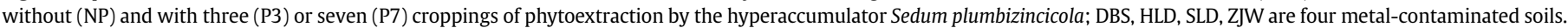

repeated phytoextraction. The metal distribution coefficient between solid and solution, $K_{\mathrm{d}}$ along with the measured $R$ value and other soil parameters (Table 3 ) were used to calculate the response time $\left(T_{\mathrm{c}}\right)$, which is the characteristic time taken by the system to approach equilibrium (Degryse et al., 2009) (Fig. 1). Soil metal desorption rate constants $\left(k_{-1}\right)$ were also calculated based on Equation (4) (Fig. 1).

In the soils without phytoextraction, $T_{\mathrm{c}}$ values were much higher in the acid soils (DBS and HLD) than the calcareous (SLD and ZJW), indicating the slow metal supply from the soil solid phase to solution in acid soils. The observed longer response time for acid soils is reasonable. Acid soils have relatively high soil solution metal concentrations but small pool sizes of metals in the solid phase, and this leads to large disturbance induced by removal of metals to the
DGT. The long response time in acid soils and short response times in calcareous soils are consistent with previous studies (Zhang et al., 2006; Ernstberger et al., 2005). After repeated phytoextraction the response time of $\mathrm{Zn}$ and $\mathrm{Cd}$ in all soils changed markedly and showed large decreases in the acid soils but there were clear increases in the calcareous soils (Fig. 1). By definition $T_{\mathrm{C}}$ is the characteristic time taken to approach equilibrium between the soil solid and solution phases and should depend on the labile metal distribution coefficient between solid and solution $\left(K_{\mathrm{d}}\right)$ and the metal desorption rate constant $\left(k_{-1}\right)$ (Degryse et al., 2009). Theoretically, the metal desorption rate cannot be enhanced after phytoextraction because more easily desorbed metal was removed firstly by the hyperaccumulator as validated by the decreased desorption rate constants $\left(k_{-1}\right)$ (Fig. 1). Thus, the decreases in 

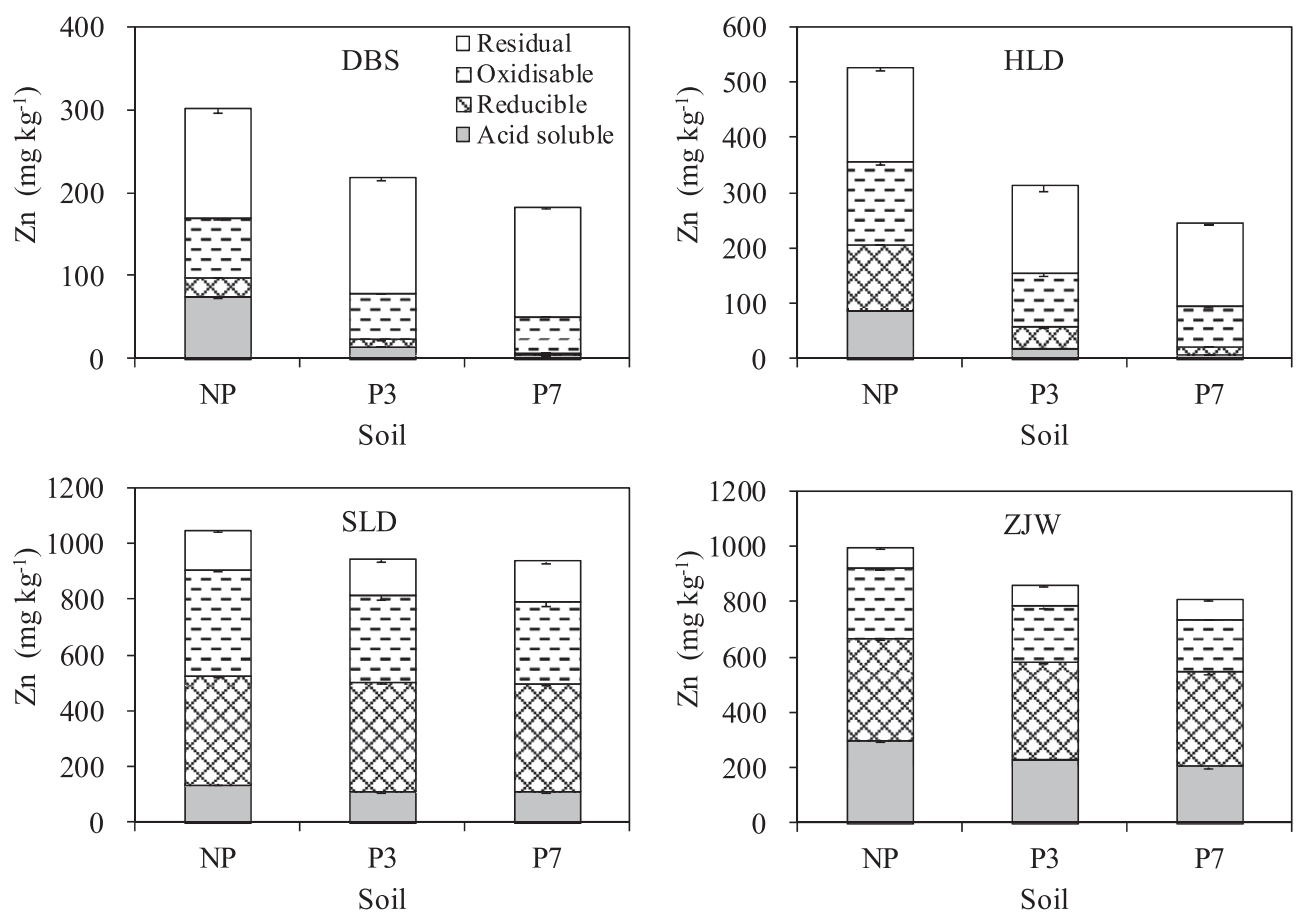

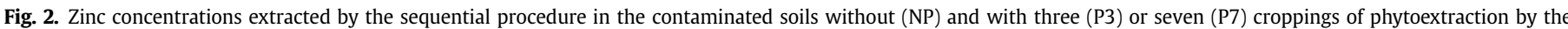
hyperaccumulator Sedum plumbizincicola; DBS, HLD, SLD, ZJW are four metal-contaminated soils; bars show the standard error of the mean.
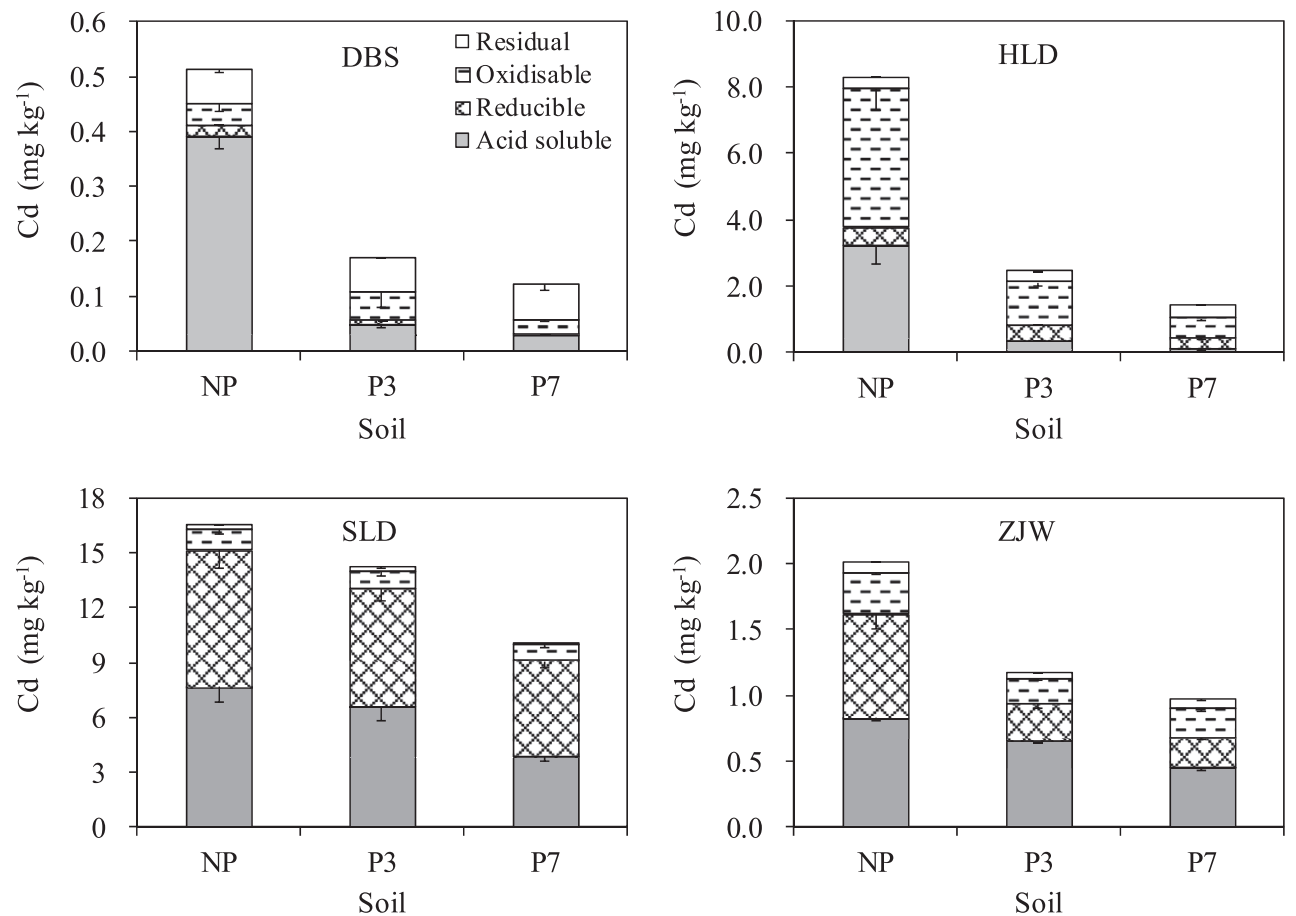

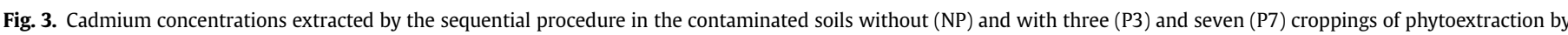
the hyperaccumulator Sedum plumbizincicola; DBS, HLD, SLD, ZJW are four metal-contaminated soils; bars show the standard error of the mean.

response time in acid soils after phytoextraction should be related to large increases in $K_{\mathrm{d}}$ as a result of the decreases of $>90 \%$ in soil solution metal (Table 3). Although in calcareous soils $K_{\mathrm{d}}$ also showed marked increases, the response time still showed an increasing trend during phytoextraction. This result indicates that the effect of the much decreased $k_{-1}$ on the response time was more profound than the effect of the increased $K_{\mathrm{d}}$ in calcareous soils as illustrated by the sharp decreases in $k_{-1}$ between soil without phytoextraction (NP) and with three crops of the hyperaccumulator (P3).

In DBS soil the $k_{-1}$ of $\mathrm{Cd}$ during repeated phytoextraction remained constant indicating that the same mechanism controls 
metal release from the soil solid phase to the soil solution (Fig. 1). This is supported by the acid soluble $\mathrm{Cd}$ being the main available fraction (Fig. 3). With the exception of Cd in DBS soil, the desorption rate constants $\left(k_{-1}\right)$ of $\mathrm{Cd}$ and $\mathrm{Zn}$ in all soils decreased greatly after repeated phytoextraction (Fig. 1 ). This indicates that there were different available metal pools controlling metal desorption during phytoextraction, and the remaining soil metal after phytoextraction had stronger binding forces to soil particles. Especially in calcareous soils, desorption rate constants showed a much more dramatic decline than in acid soils during the initial stages of phytoextraction (Fig. 1). As the target of phytoextraction is based on total metal removal, the combined decreases in soil solution metal concentrations and desorption ability indicate that phytoextraction of calcareous soils can greatly decrease soil metal mobility and the risk of metal transfer to the environment.

\subsection{Metal chemical fractions based on BCR sequential extraction}

The different extraction steps of BCR chemical extraction represent different forms of association and different mechanisms of availability (Ure et al., 1993; Anju and Banerjee, 2011). In the present study the changes in $\mathrm{Zn}$ and $\mathrm{Cd}$ chemical forms based on BCR sequential extraction in the four contaminated soils during repeated phytoextraction were investigated and the data are shown in Figs. 2 and 3.

In the soils without phytoextraction (NP), Zn distribution in the acid soils DBS and HLD followed the orders residual > acid soluble and oxidisable $>$ reducible fraction and residual $>$ oxidisable and reducible $>$ acid soluble fractions, respectively (Fig. 2). Large residual fractions of $\mathrm{Zn}$ indicate that most of the metal is background $\mathrm{Zn}$ in soil crystal lattices, a form not easily taken up by plants. This is also indicated by the absence of significant changes in residual fractions of metals after three years of phytoextraction (Figs. 2 and 3). Soil Cd in DBS was distributed mainly in the acid soluble fraction (76.3\% of total Cd), suggesting that Cd existed in highly available forms in the soil. This may result from the low soil $\mathrm{pH}$ (Table 1) which promotes the release of Cd from the soil solid phase. In HLD soil Cd was mainly partitioned in the oxidisable and acid soluble fractions (Fig. 1). Large amounts of oxidisable Cd in HLD soil may be associated with high pollution with elemental sulfur because of the activities of a zinc factory in this area (Zhu et al., 2001) promoting the binding of $\mathrm{Cd}$ mostly to the sulfide phase. During repeated phytoextraction, acid soluble $\mathrm{Zn}$ and $\mathrm{Cd}$ may have been easily taken up by $S$. plumbizincicola and were almost removed after three croppings in the acid soils (Figs. 2 and 3). Reducible and oxidisable metals also showed clear decreases during the first three croppings, indicating that these two metal fractions can also be mobilized and subsequently be taken up by $S$. plumbizincicola. In HLD soil, although soil Cd still remained in the highly available fractions (acid soluble + reducible + oxidisable, $86.4 \%$ of total) after the first three croppings of phytoextraction, the Cd removal efficiency was much lower during the subsequent four croppings. This suggests that if no other additional measures are taken to enhance metal phytoavailability, the later stages of phytoextraction will be time consuming and ineffective. Given that the oxidisable metal was the dominating fraction in the acid soils after phytoextraction when excluding the non-available residual fraction, measures to accelerate soil organic matter transformation and changing soil redox conditions might enhance the efficiency of remediation.

Soil $\mathrm{Zn}$ and $\mathrm{Cd}$ in the calcareous soils showed high potential availability based on BCR extraction. Soil Zn was partitioned mainly in the first three fractions (acid soluble + reducible and oxidisable) which accounted for 86.5 and $92.3 \%$ of the total metal in SLD and ZJW soils, respectively (Fig. 2), and soil Cd was distributed mainly in the acid soluble and reducible fractions which accounted for 91.8 and $80.6 \%$, respectively, of the total (Fig. 3). However, the Zn and Cd decreases in the calcareous soils after phytoextraction were less pronounced than those in the acid soils. Only slight decreases in acid soluble and oxidisable $\mathrm{Zn}$ were found in both calcareous soils (Fig. 2). Although there were visible declines in acid soluble, reducible and oxidisable $\mathrm{Cd}$, the removal rates were quite low and showed further decline in the low Cd polluted calcareous soil (ZJW) in the later of stages of phytoextraction (Fig. 3). Moreover, in contrast to the acid soils, after phytoextraction both calcareous soils had high remaining amounts of acid soluble $\mathrm{Zn}$ and $\mathrm{Cd}$ as well as reducible and oxidisable fractions (Figs. 2 and 3). This may have resulted from metal precipitation or strong adsorption/complexation of metals to carbonates in the high $\mathrm{pH}$ calcareous soils (Du Laing et al., 2009). These results suggest that in calcareous soils acid soluble metal is not easily removed by plants (in contrast to the acid soils) and lowering soil pH might be a necessary measure for increasing remediation efficiency.

In the present study there was no significant change in the residual metals in any of the soils (Figs. 2 and 3). This suggests that the above metal processes during phytoextraction had no effects on residual metals, the fraction unavailable to plants and not to be considered as a target of phytoextraction. This is important for phytoextraction of soils contaminated with large amounts of residual metals. If the residual metals can be ignored it is possible to increase the efficiency and shorten the time required for phytoextraction. For example, after seven croppings of phytoextraction, the soil $\mathrm{Zn}$ remaining was mostly distributed in the residual fraction, and the percentages of residual $\mathrm{Zn}$ to total were 72.3 and $61.7 \%$ for DBS and HLD soils, respectively. The remaining available $\mathrm{Zn}$ fractions (acid soluble + reducible + oxidisable) were very low (50.5 and $93.3 \mathrm{mg} \mathrm{kg}^{-1}$ ) and were already below the permissible level for agriculture soils in China $\left(200 \mathrm{mg} \mathrm{kg}^{-1}\right)$. Given that the residual fraction of $\mathrm{Zn}$ is unavailable to plants it is not necessary to achieve a target based on total metal phytoextraction. However further biological tests under greenhouse or field conditions are still required to ensure safe crop production.

\subsection{Soil metal processes during phytoextraction}

The lower metal removal in calcareous soils than in acid soils may be related to the two main soil metal processes during repeated phytoremediation. First, metal releases from the solid phase to the soil solution are based on an equilibrium principle when soil solution metal depletion is induced by plant metal uptake. In this process soil metals with a rapid desorption rate and high concentration in the soil solution might be propitious to phytoextraction. For example, the acid soil HLD showed high amounts of metal removal (Table 1). In the acid soil DBS, although the soil solution metal concentration was as high as that of HLD during repeated phytoextraction, its metal desorption ability was weak as evidenced by large response time $\left(T_{\mathrm{C}}\right)$ and low desorption rate constants $\left(k_{-1}\right)$ (Fig. 1 ), resulting in lower metal removal by plants from DBS than HLD. In the calcareous soils SLD and ZJW, although metals in NP soils showed rapid supply to solution as estimated by a small $T_{\mathrm{C}}$ and high $k_{-1}$ (Fig. 1 ), the plant metal concentrations in calcareous soils were still several times lower than those in the acid soils (Li et al., 2014). This resulted mainly from soil solution metals being one to two orders of magnitude lower in calcareous soils (Table 2). This may be one of the explanations for the low metal removal efficiency by plants in the calcareous soils. Moreover, the sharp decreases in soil solution metals (Table 2) and visible decline in metal desorption ability (indicated by $k_{-1}$ ) in the acid soils (Fig. 1) might also be the main factor responsible for the lower metal removal at the later stages of repeated phytoextraction compared to the early stages (Li et al., 2014). Interestingly, although 
the soil solution metal concentrations, metal availability and metal desorption ability showed large decreases (Table 2 and Fig. 1) during repeated phytoextraction, plant metal uptake in calcareous soil remained constant as in Li et al. (2014). This indicates that in calcareous soils metal releases based on equilibrium principles cannot explain plant metal uptake. As previous studies using isotope dilution techniques indicate, acid-soluble and part of oxidisable metals in soils can be released to the soil solution based on equilibrium principles (Ahnstrom and Parker, 2001; Marzouk et al., 2013). However, in this study soil reducible and oxidisable metal fractions in both acid and calcareous soils showed large decreases after phytoextraction (Figs. 2 and 3). These decreases also cannot be explained by the above metal process based on the equilibrium principle. Furthermore, rhizosphere activities can change plant metal accessibility and availability (Chardot-Jacques et al., 2013). The secretions of hyperaccumulator roots can enhance metal availability by decreasing soil pH or forming soluble DOM-metal complexes (Dessureault-Rompre et al., 2010; Li et al., 2013a,b). In addition, the associated microorganisms and their activities in hyperaccumulator rhizosphere soil also play a role in enhancing metal availability (Li et al., 2010; Wei and Twardowska, 2013). In addition to the microbial activities, soil bound metals can be released with the transformation of $\mathrm{Fe} / \mathrm{Al} / \mathrm{Mn}$ oxides when there is a shift in soil redox conditions (Husson, 2013) or decomposition of soil organic matter. The rhizosphere effect on metal uptake has been considered to be one of the most important mechanisms in phytoextraction using hyperaccumulators and might be responsible for the removal of reducible and oxidisable metals found after repeated phytoextraction. However, the actual mechanism and how it may be enhanced to increase remediation efficiency are still poorly understood.

\section{Conclusions}

Repeated phytoextraction can significantly decrease soil solution metal concentrations in both acid and calcareous soils; the removal of available metals (extracted by $\mathrm{CaCl}_{2}$ and EDTA) depends on the soils, with high removal efficiency in acid soils but no significant change or only slight changes in calcareous soils during phytoextraction. Metal desorption rates in all soils (with the sole exception of the low $\mathrm{pH}$ soil DBS) showed marked decreases, especially in the calcareous soils which showed a very large decline in desorption rate constant at the initial stages of phytoextraction. These results indicate that phytoextraction can reduce metal availability by decreasing the soil available metal pool size and/or metal desorption rates.

In the present study acid soluble metals were easily removed by S. plumbizincicola from acid soils during the initial stages of phytoextraction, but there was little removal from the calcareous soils. Repeated phytoextraction can remove reducible and oxidisable metals from both acid and calcareous soils but the residual metals cannot be removed. This suggests that $S$. plumbizincicola can play an important role in the mobilization of the non-labile fraction of metals during repeated phytoextraction.

\section{Acknowledgments}

This research was financially supported by the National HighTechnology Research and Development Program of China (2012AA101402-2) and the National Natural Science Foundation of China (41325003 and 41271326).

\section{References}

soils using a coupled stable isotope dilution-sequential extraction procedure. Environ. Sci. Technol. 35, 121-126.

Anju, M., Banerjee, D.K., 2011. Associations of cadmium, zinc, and lead in soils from a lead and zinc mining area as studied by single and sequential extractions. Environ. Monit. Assess. 176, 67-85.

Chardot-Jacques, V., Calvaruso, C., Simon, B., Turpault, M.P., Echevarria, G. Morel, J.L., 2013. Chrysotile dissolution in the rhizosphere of the nickel hyperaccumulator Leptoplax emarginata. Environ. Sci. Technol. 47, 2612-2620.

D'Amore, J.J., Al-Abed, S.R., Scheckel, K.G., Ryan, J.A., 2005. Methods for speciation of metals in soils: a review. J. Environ. Qual. 34, 1707-1745.

Davison, W., Hooda, P.S., Zhang, H., Edwards, A.C., 2000. DGT measured fluxes as surrogates for uptake of metals by plants. Adv. Environ. Res. 3, 550-555.

Degryse, F., Smolders, E., Zhang, H., Davison, W., 2009. Predicting availability of mineral elements to plants with the DGT technique: a review of experimental data and interpretation by modelling. Environ. Chem. 6, 198-218.

Dessureault-Rompre, J., Luster, J., Schulin, R., Tercier-Waeber, M.L., Nowack, B., 2010. Decrease of labile $\mathrm{Zn}$ and $\mathrm{Cd}$ in the rhizosphere of hyperaccumulating Thlasp caerulescens with time. Environ. Pollut. 158, 1955-1962.

Du Laing, G., Rinklebe, J., Vandecasteele, B., Meers, E., Tack, F.M.G., 2009. Trace metal behaviour in estuarine and riverine floodplain soils and sediments: a review. Sci. Total Environ. 407, 3972-3985.

Ernstberger, H., Zhang, H., Tye, A., Young, S., Davison, W., 2005. Desorption kinetics of Cd, Zn, and Ni measured in soils by DGT. Environ. Sci. Technol. 39, 1591-1597.

Fitz, W.J., Wenzel, W.W., Zhang, H., Nurmi, J., Stipek, K., Fischerova, Z., Schweiger, P., Kollensperger, G., Ma, L.Q., Stingeder, G., 2003. Rhizosphere characteristics of the arsenic hyperaccumulator Pteris vittata L. and monitoring of phytoremoval efficiency. Environ. Sci. Technol. 37, 5008-5014.

Fujii, K., 2014. Soil acidification and adaptations of plants and microorganisms in Bornean tropical forests. Ecol. Res. 29, 371-381.

Hoefer, C., Santner, J., Puschenreiter, M., Wenzel, W.W., 2015. Localized metal solubilization in the rhizosphere of Salix smithiana upon sulfur application. Environ. Sci. Technol. 49, 4522-4529.

Houba, V.J.G., Temminghoff, E.J.M., Gaikhorst, G.A., van Vark, W., 2000. Soil analysis procedures using $0.01 \mathrm{M}$ calcium chloride as extraction reagent. Commun. Soil Sci. Plant Anal. 31, 1299-1369.

Husson, O., 2013. Redox potential (Eh) and pH as drivers of soil/plant/microorganism systems: a transdisciplinary overview pointing to integrative opportunities for agronomy. Plant Soil 362, 389-417.

Japenga, J., Koopmans, G.F., Song, J., Roemkens, P.F.A.M., 2007. A feasibility test to estimate the duration of phytoextraction of heavy metals from polluted soils. Int. J. Phytoremediat. 9, 115-132.

Keller, C., Hammer, D., 2004. Metal availability and soil toxicity after repeated croppings of Thlaspi caerulescens in metal contaminated soils. Environ. Pollut $131,243-254$.

Koopmans, G.F., Romkens, P.F.A.M., Fokkema, M.J., Song, J., Luo, Y.M., Japenga, J. Zhao, F.J., 2008. Feasibility of phytoextraction to remediate cadmium and zinc contaminated soils. Environ. Pollut. 156, 905-914.

Li, W.C. Ye, Z.H., Wong, M.H., 2010. Metal mobilization and production of shortchain organic acids by rhizosphere bacteria associated with a $\mathrm{Cd} / \mathrm{Zn}$ hyperaccumulating plant, Sedum alfredii. Plant Soil 326, 453-467.

Li, J.T., Baker, A.J.M., Ye, Z.H., Wang, H.B., Shu, W.S., 2012. Phytoextraction of Cd contaminated soils: current status and future challenges. Crit. Rev. Environ. Sci. Technol. 42, 2113-2152.

Li, T.Q., Tao, Q., Liang, C.F., Shohag, M.J.I., Yang, X.E., Sparks, D.L., 2013a. Complexation with dissolved organic matter and mobility control of heavy metals in the rhizosphere of hyperaccumulator Sedum alfredii. Environ. Pollut. 182, 248-255.

Li, T.Q., Liang, C.F., Han, X., Yang, X.E., 2013b. Mobilization of cadmium by dissolved organic matter in the rhizosphere of hyperaccumulator Sedum alfredii. Chemosphere 91, 970-976.

Li, Z., Wu, L.H., Hu, P.J., Luo, Y.M., Zhang, H., Christie, P., 2014. Repeated phytoextraction of four metal-contaminated soils using the cadmium/zinc hyperaccumulator Sedum plumbizincicola. Environ. Pollut. 189, 176-183.

Liu, L., Wu, L.H., Li, N., Luo, Y.M., Li, S.L., Li, Z., Han, C.L., Jiang, Y.G., Christie, P., 2011. Rhizosphere concentrations of zinc and cadmium in a metal contaminated soil after repeated phytoextraction by Sedum plumbizincicola. Int. J. Phytoremed. 13, $750-764$.

Luo, Y.M., Christie, P., 1998. Choice of extraction technique for soil reducible trace metals determines the subsequent oxidisable metal fraction in sequentia extraction schemes. Int. J. Environ. Anal. Chem. 72, 59-75.

Marzouk, E.R., Chenery, S.R., Young, S.D., 2013. Measuring reactive metal in soil: a comparison of multi-element isotopic dilution and chemical extraction. Eur. J. Soil Sci. 64, 526-536.

McGrath, S.P., Lombi, E., Gray, C.W., Caille, N., Dunham, S.J., Zhao, F.J., 2006. Field evaluation of $\mathrm{Cd}$ and $\mathrm{Zn}$ phytoextraction potential by the hyperaccumulators Thlaspi caerulescens and Arabidopsis halleri. Environ. Pollut. 141, 115-125.

Meers, E., Du Laing, G., Unamuno, V., Ruttens, A., Vangronsveld, J., Tack, F.M.G. Verloo, M.G., 2007a. Comparison of cadmium extractability from soils by commonly used single extraction protocols. Geoderma 141, 247-259.

Meers, E., Samson, R., Tack, F.M.G., Ruttens, A., Vandegehuchte, M., Vangronsveld, J. Verloo, M.G., 2007b. Phytoavailability assessment of heavy metals in soils by single extractions and accumulation by Phaseolus vulgaris. Environ. Exp. Bot. 60, 385-396.

Novozamsky, I., Lexmond, T.M., Houba, V.J.G., 1993. A single extraction procedure of soil for evaluation of uptake of some metals by plants. Int. J. Environ. Anal. Chem. 51, 47-58 
Peijnenburg, W.J.G.M., Zablotskaja, M., Vijver, M.G., 2007. Monitoring metals in terrestrial environments within a bioavailability framework and a focus on soil extraction. Ecotoxicol. Environ. Saf. 67, 163-179.

Pueyo, M., Mateu, J., Rigol, A., Vidal, M., Lopez-Sanchez, J.F., Rauret, G., 2008. Use of the modified BCR three-step sequential extraction procedure for the study of trace element dynamics in contaminated soils. Environ. Pollut. 152, 330-341.

Sahuquillo, A., Lopez-Sanchez, J.F., Rubio, R., Rauret, G., Thomas, R.P., Davidson, C.M. Ure, A.M., 1999. Use of a certified reference material for extractable trace metals to assess sources of uncertainty in the BCR three-stage sequential extraction procedure. Anal. Chim. Acta 382, 317-327.

Seguin, V., Gagnon, C., Courchesne, F., 2004. Changes in water extractable metals, $\mathrm{pH}$ and organic carbon concentrations at the soil-root interface of forested soils. Plant Soil 260, 1-17.
Ure, A.M., Quevauviller, Ph, Muntau, H., Griepink, B., 1993. Speciation of heavy metals in soils and sediments. An account of the improvement and harmonization of extraction techniques undertaken under the auspices of the BCR of the Commission of the European Communities. Int. J. Environ. Anal. Chem. 51, 135-151.

Wei, S., Twardowska, I., 2013. Main rhizosphere characteristics of the Cd hyperaccumulator Rorippa globosa (Turcz.) Thell. Plant Soil 372, 669-681.

Zhang, H., Davison, W., Tye, A.M., Crout, N.M.J., Young, S.D., 2006. Kinetics of zinc and cadmium release in freshly contaminated soils. Environ. Toxicol. Chem. 25, 664-670.

Zhu, C.Y., Yi, Y.L., Zhang, Y.L., Xu, Z.L., Liu, X.Y., 2001. The effect of $\mathrm{SO}_{2}$ discharge on soils in the Huludao area. Chin. J. Soil Sci. 32, 286-288 (in Chinese). 